Louisiana State University

LSU Digital Commons

Faculty Publications

Department of Biological Sciences

$10-1-2013$

\title{
Chemical attraction of Dermacentor variabilis ticks parasitic to Peromyscus leucopus based on host body mass and sex
}

Tad Dallas

University of Georgia

Stephanie Foré

Truman State University

Follow this and additional works at: https://digitalcommons.Isu.edu/biosci_pubs

\section{Recommended Citation}

Dallas, T., \& Foré, S. (2013). Chemical attraction of Dermacentor variabilis ticks parasitic to Peromyscus leucopus based on host body mass and sex. Experimental and Applied Acarology, 61 (2), 243-250. https://doi.org/10.1007/s10493-013-9690-x

This Article is brought to you for free and open access by the Department of Biological Sciences at LSU Digital Commons. It has been accepted for inclusion in Faculty Publications by an authorized administrator of LSU Digital Commons. For more information, please contact ir@lsu.edu. 


\title{
Chemical attraction of Dermacentor variabilis ticks parasitic to Peromyscus leucopus based on host body mass and sex
}

\author{
Tad Dallas · Stephanie Foré
}

Received: 15 December 2012/ Accepted: 18 March 2013/Published online: 31 March 2013

(C) Springer Science+Business Media Dordrecht 2013

\begin{abstract}
Macroparasites are commonly aggregated on a small subset of a host population. Previous explanations for this aggregation relate to differences in immunocompetence or the degree to which hosts encounter parasites. We propose active tick host choice through chemical attraction as a potential mechanism leading to aggregated tick burdens. We test this hypothesis using a Y-maze olfactometer, comparing chemical attraction responses of larval and nymphal Dermacentor variabilis ticks parasitic to the white-footed mouse, Peromyscus leucopus, as a function of host sex and host body mass. We hypothesized that larger hosts and male hosts would be most attractive to searching ticks, as these hosts commonly have higher tick burdens in the field. Chemical attraction trials were run in the presence and absence of a known tick attractant, host-produced carbon dioxide $\left(\mathrm{CO}_{2}\right)$. Male hosts and larger hosts were preferred by nymphal $D$. variabilis in the presence and absence of $\mathrm{CO}_{2}$, whereas larvae had no detectable host preference. The current study suggests that host-produced chemical cues may promote aggregated tick burdens among hosts of a single species based on host body mass and sex.
\end{abstract}

Keywords Sex-biased parasitism - Mass-biased parasitism - Y-maze · Kairomones · American dog tick

\section{Introduction}

Parasites, and ticks in particular, can impact host fitness by enhancing mortality in heavily infected hosts (Musante et al. 2007; Hwang and Kuang 2005). Host preferences are welldocumented (Wells et al. 2012; Nava and Guglielmone 2012) with differences in host competencies (Kollars et al. 2000), habitat preferences (Campbell and MacKay 1979), body size (Gallivan and Horak 1997), and/or developmental status (Heylen and Matthysen 2011) cited as causal mechanisms.

T. Dallas $(\bowtie)$

Odum School of Ecology, University of Georgia, Athens, GA 30606, USA

e-mail: tad.dallas@drakeresearchlab.com

S. Foré

Department of Biology, Truman State University, Kirksville, MO 63501, USA 
Tick burdens are also aggregated within host populations (Ostfeld et al. 1996), likely relating to variation in host susceptibility, mediated by differences in host body mass, sex, genetics, behavior or immune investment (Wilson et al. 2002). Larger individuals and male hosts commonly have higher macroparasite intensities in field populations (Dallas et al. 2012; Harrison et al. 2009; Kiffner et al. 2011). However, the causal mechanisms underlying biases in parasitism remain disputed (Krasnov et al. 2012). Traditional explanations of mass-biased parasitism relate to the elevated energetic demands, home range sizes, and encounter probabilities of larger hosts (Wilson et al. 2002). Whereas many potential causal mechanisms relate to host behavior, genetics, or immunity, the role of tick behavior in shaping aggregated tick burdens remains less clear.

As the successful acquisition of a bloodmeal is central to tick survival and reproduction, the ability to differentiate suitable from unsuitable hosts would provide clear fitness advantages. For example, larval Ixodes scapularis molting success depends on the host species being parasitized, providing a direct link between parasite fitness and host preference (Brunner et al. 2011). Host derivatives such as host odor (Carroll 1999; Crooks and Randolph 2006; Shaw et al. 2003), feces of sick animals (Bunnell et al. 2011), skin lipids (Yoder et al. 1998), uric acid (Yoder et al. 2003) and $\mathrm{CO}_{2}$ (Wilson et al. 1972) have been implicated in increased tick chemical attraction and host differentiation. Although host cues tend to attract nymphal ticks strongly (Slowik and Lane 2009), evidence for larval tick attraction is variable, as larval Ixodes hirsti (Oorebeek et al. 2009) and Argas cooleyi (Howell 1975) exhibit attraction to host cues, but larval I. scapularis and Ixodes pacificus do not (James and Oliver 1990).

The potential preferential selection of host individuals within a species as a result of host-produced chemical cues is a largely unexplored research avenue (but see Khokhlova et al. 2011), and a potential driver of heterogeneous tick burdens observed in field populations. The white-footed mouse (Peromyscus leucopus) serves as the principal host for immature (larval and nymphal) D. variabilis (American dog tick) in our study site (Adair County, MO, USA), harboring a disproportionately high number of ticks relative to other sympatric host species (Kollars 1996). Our previous work in this system suggests that $D$. variabilis intensities on white-footed mice are elevated on larger hosts and male hosts (Dallas et al. 2012). The current study aimed to address the influence of hostproduced chemical cues on larval and nymphal $D$. variabilis host preference. To accomplish this, we first evaluated larval and nymphal D. variabilis attraction towards white-footed mice versus a control using a two-choice experimental apparatus. After the presence of chemical attraction was determined, we assessed how host body mass or sex altered this attraction response, both in the presence and absence of a known host-derived attractant (respiratory $\mathrm{CO}_{2}$ ). We predicted that larger mice and male mice would be preferred by $D$. variabilis as a result of either the amount of chemical cue produced (assuming larger hosts produce more chemical cues) or the composition of chemical cues produced, as males and females vary in chemical cue production (Kimoto et al. 2005, 2007).

\section{Methods}

Study organisms

Ticks used in this experiment were larval and nymphal $D$. variabilis from laboratory colonies, originating from local field-caught ticks, maintained by Dr. Laura Fielden at 
Truman State University (Kirksville, MO, USA). All D. variabilis were non-fed and sex ratios were presumed to be equal. Ticks were maintained at $25{ }^{\circ} \mathrm{C}$ in an incubator kept at $92.5 \%$ relative humidity $(\mathrm{RH})$ with $\mathrm{KNO}_{3}$ solution (Winston and Bates 1960) and at a 12:12 (light:dark) photoperiod.

White-footed mice were trapped in Adair County, Missouri, and kept in laboratory colonies, housed in polypropylene cages $(28 \mathrm{~cm}$ long $\times 21 \mathrm{~cm}$ wide $\times 15 \mathrm{~cm}$ high) covered with stainless steel wire lids, and fed laboratory grade rodent diet \#5001 (PMI Nutritional, Brentwood, MO, USA). All animals were maintained at $21 \pm 2{ }^{\circ} \mathrm{C}$ and 12:12 (light:dark) photoperiod for at least 2 weeks before choice trials and were handled according to the American Society of Mammalogists' standards (Gannon and Sikes 2007).

\section{Experimental design}

A Y-maze olfactometer was used to quantify attraction responses (Fig. 1). The experimental apparatus consisted of two $850 \mathrm{ml}$ holding chambers (Qubit Systems) for containment of two small mammal hosts with laminar airflow at $0.3 \mathrm{~L} \mathrm{~min}^{-1}$ to each of the chambers provided by separate air pumps. Air was forced through a column of water before entering the host chamber in order to keep the relative humidity inside the experimental chambers constant $(80 \pm 5 \%)$ and to prevent dessication of ticks. A $6 \mathrm{~cm}$ length of Tygon tubing connected the animal chamber to a Pyrex glass Y-maze $(4.0 \mathrm{~mm}$ inner diameter). The Y-maze itself had a $4 \mathrm{~cm}$ long stem where ticks were introduced and two $8 \mathrm{~cm}$ long arms splitting off to each of the two odor sources. In some trials, $\mathrm{CO}_{2}$ was removed by placing soda lime inserts between the holding chamber and the Y-maze to test for attraction to the host based on chemical cues other than $\mathrm{CO}_{2}$. Similar structures have been used extensively to test attraction responses in mites (Gnanvossou et al. 2003), ticks (Slowik and Lane 2009), eulophid parasitoids (Trexler 1985), fleas (Khokhlova et al. 2011) and psyllids (Patt and Setamou 2010). Tests of the Y-maze design have demonstrated no significant difference in chemical attraction response between Y-maze and four-way olfactometers (de Kogel et al. 1999).

The Y-maze design allowed for pairwise choice trials. Hosts were given $10 \mathrm{~min}$ to saturate the experimental chamber with odor before trials began. After this period, 10 ticks

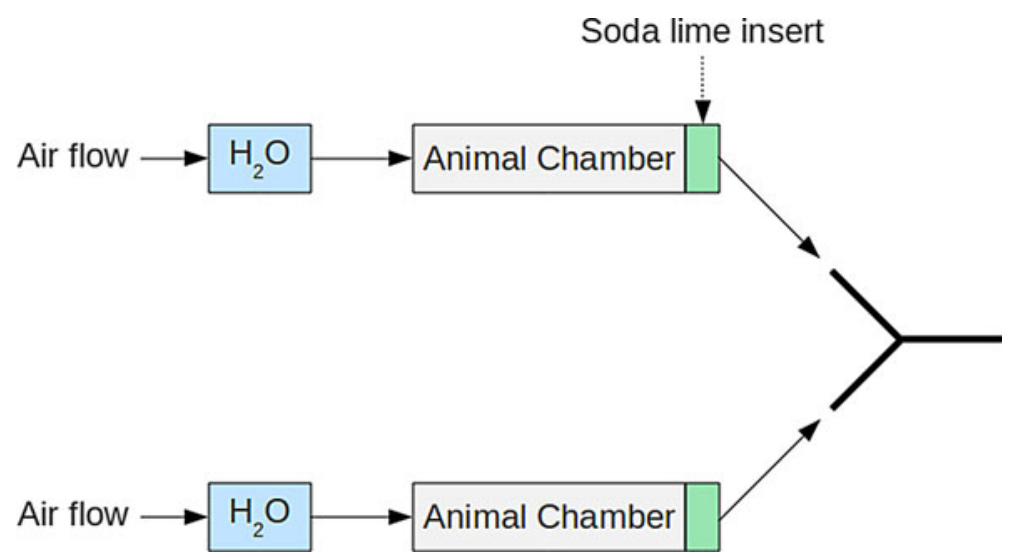

Fig. 1 A simplified diagram depicting the Y-maze olfactometer used to test chemical attraction in $D$. variabilis. The direction of air flow is indicated by the arrows 
were placed in the end of the Y-maze olfactometer and given 15 min to move towards either host, a duration based on previous olfactometry studies (Slowik and Lane 2009; Shaw et al. 1998) and preliminary trials monitoring tick movement at intervals between 5 and 60 minutes. Ticks were selected randomly for each trial and used only once. To remove the influence of attraction towards a light source, and because larval and nymphal Dermacentor species are more active at night (Lane et al. 1995; Conlon and Rockett 1982), all trials were run in the absence of light and within the dark cycle of the 12:12 (light:dark) photoperiod of $D$. variabilis. After each trial the chambers were alternated to eliminate directional bias and the Y-maze was washed with $95 \%$ alcohol, rinsed with deionized water and dried. Trials in which fewer than five ticks oriented towards either host (i.e., those not moving from the stem of the Y-maze) or those with excess condensation in the Y-maze were not considered in data analysis, as excess condensation could restrict tick movement. Four replicate trials were conducted for each pairwise combination of possible host choices with attraction decided by taking the average attraction of the four trials to obtain a composite attraction measure for the pair.

To test if $D$. variabilis could differentiate a host from a control, we performed attraction trials using a primary host (white-footed mouse) and a stone of comparable mass to a white-footed mouse in order to disrupt laminar airflow through the chamber in a way similar to a white-footed mouse. The control was rinsed with deionized water and placed in bedding used in our animal cages (Aspen Shavings, NEPCO). Trials were performed in the absence of $\mathrm{CO}_{2}$ to eliminate bias not based on host odor. A total of 26 P. leucopuscontrol pairs ( 8 females, 18 males) were examined for $D$. variabilis nymphal attraction and 11 pairs ( 5 females, 6 males) were used to examine $D$. variabilis larvae.

The effect of body mass was tested by comparing large $(>24 \mathrm{~g})$ and small $(<22 \mathrm{~g})$ pairs of white-footed mice, the sex being the same, and the effect of sex was tested by comparing male and female white-footed mice of similar body mass. Body mass was maintained by feeding large animals ad libitum while small animals were fed 10-12 g per week. A total of 18 P. leucopus pairs were used to test the effect of host body mass, and 20 pairs to test the effect of host sex on chemical attraction of $D$. variabilis. Trials were performed on these pairs both in the presence and absence of $\mathrm{CO}_{2}$, in order to determine how $\mathrm{CO}_{2}$ influenced nymphal $D$. variabilis chemical attraction.

\section{Data analyses}

Attraction data were based on the results of four attraction trials per host pair, averaged together to determine tick choice. Binomial exact tests were used to test whether tick choices differed significantly from no preference (i.e., probability of either host being chosen is 0.5). These tests were applied to the comparisons of attraction to host over control and attraction based on host mass or host sex. Binomial exact tests are ideal when sample size is not large enough to allow for Chi-squared approximation. The influence of $\mathrm{CO}_{2}$ on the attraction response was examined using Fisher's exact tests, with the null hypothesis stating that the relative proportions of tick attraction based on host body mass or sex do not significantly differ as a result of $\mathrm{CO}_{2}$. In other words, the odds of tick chemoattraction in the presence of $\mathrm{CO}_{2}$ divided by the odds of tick attraction in the absence of $\mathrm{CO}_{2}$ is 1 (i.e., the odds ratio (OR) does not differ significantly from 1). All analyses were performed in the R statistical computing environment (R Core Team 2012), using an $\alpha$-value of 0.05 . 


\section{Results}

\section{Baseline attraction}

Larval ticks exhibited no host preference (e.g. $15 \%$ of attraction trials resulted in choice of either host) and very little ambulatory response from where they were placed at the start of the attraction trial. Given the low attraction response, we were unable to accurately assess the presence of larval tick chemical attraction. As a result, only nymphal $D$. variabilis were used to examine host preferences based on host body mass or sex. Host-mediated attraction responses were observed when comparing nymphal $D$. variabilis preference between a control and white-footed mice (Table 1). This response remained when considering male $(p=0.0002)$ and female $(p=0.008)$ hosts separately.

Host body mass and sex as attraction determinants

Nymphal D. variabilis selected male white-footed mice more often than expected by chance in both the presence and absence of $\mathrm{CO}_{2}$, with 19 and 18 trials resulting in significant male host preference, respectively. Further, larger mice were preferred over smaller mice, with 16 and 17 trials out of 18 trials resulting in preference towards the larger host in both $\mathrm{CO}_{2}$ presence and absence treatments, respectively (Table 1). Host-produced $\mathrm{CO}_{2}$ did not alter the host preferences towards larger hosts $(\mathrm{OR}=2.08, p>0.5)$ or male hosts $(\mathrm{OR}=0.482, p>0.5)$.

\section{Discussion}

Larval D. variabilis did not exhibit a preference to white-footed mice based on hostproduced cues. Similar findings of no effect of host odor on larval tick attraction have been reported for I. hirsti (Oorebeek et al. 2009) and A. cooleyi (Howell 1975), but are counter

Table 1 The results of chemical attraction trials examining tick preferences to white-footed mice over a control ("baseline"), towards larger mice ("host body mass"), and towards males ("host sex")

\begin{tabular}{lllrll}
\hline & $\mathrm{CO}_{2}$ presence & Host & Choice & CI & $p$ \\
\hline Baseline & + & P. leucopus & 25 & $0.80-1.0$ & $<0.001$ \\
& & Control & 1 & & \\
Host body mass & + & Large & 16 & $0.65-1.0$ & $<0.001$ \\
& & Small & 2 & & \\
& - & Large & 17 & $0.73-1.0$ & $<0.001$ \\
Host sex & Small & 1 & & \\
& + & Male & 19 & $0.75-1.0$ & $<0.001$ \\
& - & Female & 1 & & \\
& & Male & 18 & $0.68-1.0$ & $<0.001$ \\
\hline
\end{tabular}

The number of successful trials for a given choice is given by "choice". Binomial confidence intervals are provided around the probability that a trial will result in tick selection of (a) white-footed mice relative to a control, (b) large hosts over small hosts, and (c) male hosts instead of female hosts. The $p$ values are from binomial exact tests, providing the probability that the actual proportion of trials resulting in a host preference does not differ from equiprobable host choice 
reports of larval I. scapularis and I. pacificus attraction to host cues (James and Oliver 1990). Slowik and Lane (2009) suggest that attraction responses observed in larval $I$. pacificus, I. jellisoni and D. occidentalis among avian, reptile and rodent hosts in an open air olfactometer, were random searching behavior as seen in Hyalomma marginatum (Buczek et al. 1998) as larval ticks have underdeveloped Haller's organs. The lack of larval chemoattraction response suggests that other factors (i.e., maternal egg batch placement, position in leaf litter, etc.) may promote host preferences of larvae, as many larval Ixodids exhibit host specificity in the field (Kollars 1996; Kollars et al. 2000).

Nymphal $D$. variabilis actively oriented towards white-footed mice hosts based on sex and mass in the presence and absence of $\mathrm{CO}_{2}$, preferring males over females and larger mice over smaller individuals. Proposed explanations of sex-biased parasitism have focused on differences in behavior and immunocompetence between males and females (Krasnov et al. 2005; Sheridan et al. 2000). The present study suggests that there is a chemical difference between male and female white-footed mice that nymphal $D$. variabilis can sense. This chemical difference may affect the probability of successful host acquisition, enhancing sexbiased parasitism observed in field studies. Ticks may be adapted to search for hosts on which they have the highest likelihood of obtaining a successful bloodmeal. As testosterone lowers immunocompetence in males (Grossman 1985), male hosts are potentially preferred by ticks. Larger individuals were preferred over smaller individuals, potentially owing to the amount of chemical cue produced by larger individuals. This result is consistent with field observations in this study location and system (Dallas et al. 2012) and other study areas (Harrison et al. 2009). While we acknowledge the possibility that intrinsic differences between hosts in Y-maze trials may have created moisture gradients or detectable mechanical disturbances, hosts remained still during experimental trials and trials in which noticeable condensation were removed from the analysis.

The attraction responses to larger hosts and to males were not affected by the presence of $\mathrm{CO}_{2}$, suggesting that host-produced chemicals are important tick attractants regardless of $\mathrm{CO}_{2}$, a documented tick attractant (Steullet and Guerin 1992; Garcia 1962). It is possible that pheromones and other chemical cues outweigh the influence of $\mathrm{CO}_{2}$ on tick chemical attraction. However, $\mathrm{CO}_{2}$ may play a larger role at greater distances, as the current experiment placed ticks in close proximity to hosts, potentially biasing the relative importance of host cues and $\mathrm{CO}_{2}$.

The significant intraspecific attraction response of D. variabilis to P. leucopus may lead to the biased parasitism observed in field studies. However, chemical attraction is likely a single element in a suite of factors responsible for variable tick burdens in wild host populations. Efforts to quantify differences in home range size, immune profile, and behavior among individuals of different sex and body mass will provide a more complete picture of the ecological factors responsible for biases in tick host preferences within a single host species.

Acknowledgments This work was supported by the National Science Foundation under Grant No. 0431664 and No. 0436348 and by a Phi Kappa Phi Love of Learning grant. We thank A. Kramer, S. Maher, and several anonymous reviewers for helpful comments on the manuscript.

\section{References}

Brunner J, Cheney L, Keesing F, Killilea M, Logiudice K, Previtali A, Ostfeld R (2011) Molting success of Ixodes scapularis varies among individual blood meal hosts and species. $\mathrm{J}$ Med Entomol 48(4):860-866 
Buczek A, Jasik K, Buczek L (1998) Sense organs in post-embryonic stages of Hyalomma marginatum marginatum Koch, 1844 (Acari: Ixodida, Ixodidae) I. Tarsal sensory system. Parassitologia 40:279-282

Bunnell T, Hanisch K, Hardege JD, Breithaupt T (2011) The fecal odor of sick hedgehogs (Erinaceus europaeus) mediates olfactory attraction of the tick Ixodes hexagonus. J Chem Ecol 37(4):340-347

Campbell A, MacKay P (1979) Distribution of the American dog tick, Dermacentor variabilis (Say), and its small-mammal hosts in relation to vegetation types in a study area in Nova Scotia. Can J Zool 57:1950-1959

Carroll J (1999) Responses of three species of adult ticks (Acari:Ixodidae) to chemicals in the coats of principal and minor hosts. J Med Entomol 36(3):342-368

Conlon J, Rockett C (1982) Ecological investigations of the american dog tick, Dermacentor variabilis (Say), in northwest ohio (Acari: Ixodidae). Int J Acarol 8(3):125-131

Crooks E, Randolph SE (2006) Walking by Ixodes ricinus ticks: intrinsic and extrinsic factors determine the attraction of moisture or host odour. J Exp Biol 209:2138-2142

Dallas T, Foré S, Kim HJ (2012) Modeling the influence of Peromyscus leucopus body mass, sex and habitat on immature Dermacentor variabilis burdens. J Vector Ecol 37(2):338-341

de Kogel WJ, Koschier EH, Visser JH (1999) Y-tube olfactometer to determine the attractiveness of plant volatiles to western flower thrips. Proc Exp Appl Entomol 10:131-135

Gallivan G, Horak I (1997) Body size and habitat as determinants of tick infestations of wild ungulates in South Africa. S Afr J Wildl Res 27(2):63-70

Gannon W, Sikes R (2007) Guidelines of the American Society of Mammalogists for the use of wild mammals in research. J Mammal 88(3):809-823

Garcia R (1962) Carbon dioxide as an attractant for certain ticks (Acarina: Argasidae and Ixodidae). Ann Entomol Soc Am 55(5):605-606

Gnanvossou D, Hanna R, Dicke M (2003) Infochemical-mediated intraguild interactions among three predatory mites on cassava plants. Oecologia 135(1):84-90

Grossman C (1985) Interactions between the gonadal-steroids and the immune system. Science 227:257-261

Harrison A, Scantlebury M, Montgomery WI (2009) Body mass and sex-biased parasitism in wood mice Apodemus sylvaticus. Oikos 119(7):1099-1104

Heylen D, Matthysen E (2011) Experimental evidence for host preference in a tick parasitizing songbird nestlings. Oikos 120(8):1209-1216

Howell FG (1975) The roles of host-related stimuli in the behavior of Argas cooleyi (Acarina: Argasidae). J Med Entomol 11:715-723

Hwang TW, Kuang Y (2005) Host extinction dynamics in a simple parasite-host interaction model. Math Biosci Eng 2:743-751

James A, Oliver J (1990) Feeding and host preference of immature Ixodes dammini, I. scapularis, and I. pacificus (Acari:Ixodidae). J Med Entomol 40:319-327

Khokhlova IS, Serobyan V, Degen AA, Krasnov BR (2011) Discrimination of host sex by a haematophagous ectoparasite. Anim Behav 81(1):275-281

Kiffner C, Lödige C, Alings M, Vor T, Rühe F (2011) Body-mass or sex-biased tick parasitism in roe deer (Capreolus capreolus)? A GAMLSS approach. Med Vet Entomol 25(1):39-45

Kimoto H, Haga S, Sato K, Touhara K (2005) Sex-specific peptides from exocrine glands stimulate mouse vomeronasal sensory neurons. Nature 437:898-901

Kimoto H, Sato K, Nodari F, Haga S, Holy TE, Touhara K (2007) Sex- and strain-specific expression and vomeronasal activity of mouse ESP family peptides. Curr Biol 17:1879-1884

Kollars TM (1996) Interspecific differences between small mammals as hosts of immature Dermacentor variabilis (acari: Ixodidae) and a model for detection of high risk areas of rocky mountain spotted fever. J Parasitol 707-710

Kollars TM, Oliver JHJ, Durden LA, Kollars PG (2000) Host associations and seasonal activity of Amblyomma americanum (Acari: Ixodidae) in Missouri. J Parasitol 86(5):1156-1159

Krasnov BR, Morand S, Hawlena H, Khokhlova IS, Shenbrot GI (2005) Sex-biased parasitism, seasonality, and sexual size dimorphism in desert rodents. Oecologia 146(2):209-217

Krasnov BR, Bordes F, Khokhlova IS, Morand S (2012) Gender-biased parasitism in small mammals: patterns, mechanisms, consequences. Mammalia 76(1):1-13

Lane RS, Kleinjan JE, Schoeler GB (1995) Diel activity of nymphal Dermacentor occidentalis and Ixodes pacificus in relation to meteorological factors and host activity periods. J Med Entomol 32(3):290-299

Musante AR, Pekins PJ, Scarpitti DL (2007) Metabolic impacts of winter tick infestations on calf moose. Alces 43:101-107 
Nava S, Guglielmone AA (2012) A meta-analysis of host specificity in Neotropical hard ticks (Acari: Ixodidae). Bull Entomol Res 1(1):1-9

Oorebeek M, Sharrad R, Kleindorfer S (2009) What attracts larval Ixodes hirsti (Acari: Ixodidae) to their host? Parasitol Res 104(3):623-628

Ostfeld RS, Miller MC, Hazler KR (1996) Causes and consequences of tick (Ixodes scapularis) burdens on white-footed mice (Peromyscus leucopus). Am Soc Mammal 77(1):266-273

Patt J, Setamou M (2010) Responses of the asian citrus psyllid to volatiles emitted by the flushing shoots of its rutaceous host plants. Environ Entomol 39(2):618-624

R Core Team (2012) R: A language and environment for statistical computing. R Foundation for Statistical Computing, Vienna, Austria. ISBN 3-900051-07-0, URL http://www.R-project.org/

Shaw D, Grenfell B, Dobson A (1998) Patterns of macroparasite aggregation in wildlife host populations. Parasitology 117:597-610

Shaw MT, Keesing F, McGrail R, Ostfeld RS (2003) Factors influencing the distribution of larval blacklegged ticks on rodent hosts. Am J Trop Med Hyg 68(4):447-452

Sheridan LA, Poulin R, Ward DF, Zuk M (2000) Sex differences in parasitic infections among arthropod hosts: is there a male bias? Oikos $88: 327-334$

Slowik T, Lane R (2009) Feeding preferences of the immature stages of three western North American Ixodid ticks (Acari) for avian, reptilian or rodent hosts. J Med Entomol 46(1):115-122

Steullet P, Guerin P (1992) Perception of breath components by the tropical bont tick, Amblyomma variegatum fabricius (Ixodidae). J Comp Physiol A: Neuroethol Sens Neural Behav Physiol 170(6):665-676

Trexler, JC (1985) Density-dependent parasitism by a eulophid parasitoid: tests of an intragenerational hypothesis. Oikos 415-422

Wells K, O’Hara RB, Pfeiffer M, Lakim MB, Petney TN, and Durden LA (2012) Inferring host specificity and network formation through agent-based models: tick-mammal interactions in Borneo. Oecologia $1-10$

Wilson J, Kinzer D, Sauer J, Hair J (1972) Chemo-attraction in the lone star tick (Acarina:Ixodidae): response of different developmental stages to carbon dioxide administered via traps. J Med Entomol $9(3): 245-252$

Wilson K, Bjornstad O, Dobson A, Merler S, Poglayen G, Randolph S, Read A, Skorping A (2002) Heterogeneities in macroparasite infections: patterns and processes. In: Hudson PJ, Rizzoli A, Grenfell BT, Heesterbeek H, Dobson AP (eds) The ecology of wildlife diseases. Oxford University Press, Oxford

Winston PW, Bates DH (1960) Saturated solutions for the control of humidity in biological research. Ecology 41(1):232-237

Yoder J, Atwood A, Stevens B (1998) Attraction to squalene by ticks (Acari: Ixodidae); first demonstration of a host-derived attractant. Int J Acarol 24(2):143-147

Yoder JA, Domingus JL, Luerman GC (2003) Uric acid-induced arrestment as a possible bird host cue (kairomone) in nymphs and adults of the lone star tick, Amblyomma americanum (L.). Int J Parasitol 29(4):399-402 